\title{
Land Degradation and Challenges of Food Security
}

\author{
Gauri Shankar Gupta
}

Correspondence: Széchenyi University’s Doctoral Program in Management (SzEEDSM), Doctoral School of Regional Sciences and Business Administration, Széchenyi István University, 9026 Györ, Egyetem sqare 1. Hungary. E-mail: gaurishankargupta@yahoo.co.in

\author{
Received: November 6, 2018 Accepted: January 14, 2019 Online Published: January 25, 2019 \\ doi:10.5539/res.v11n1p63 \\ URL: https://doi.org/10.5539/res.v11n1p63
}

\begin{abstract}
Land degradation has emerged as a serious problem during the last few decades. Soil fertility has declined considerably in many parts of the world due to intensive agriculture, over-grazing, water pollution, increasing use of fertilizers and pesticides, salinization, deforestation and accumulation of non-biodegradable waste. Vast tracts of land are facing desertification. Climate change is further aggravating land degradation, soil erosion and soil fertility. Evidence suggests during the last 6-7 decades over 35 percent of arable land has been degraded due to human induced activities. Soil being the natural medium for plant growth supports all life on earth. Rapidly increasing population, growing food-waste and declining soil fertility are posing serious challenges to humanity for future food security. Therefore, land degradation must come to a halt. Education, changes in agricultural policy and technological innovations are instruments that should be used for restoration of degraded land and stop further land degradation.
\end{abstract}

Keywords: land degradation, soil fertility, arable land, salinization, deforestation, desertification, population growth, food security

\section{Introduction}

Land is the primary source for sustenance of all forms of life on earth. Soil is the most precious of all resources as it sustains plants and vegetation which provide food and nourishment for all living beings. During the last seven decades; due to rapidly increasing population, rise in per capita income, change in dietary habits, mounting wastage of food and transmission losses; demand for food has gone up substantially. Sizeable amount of arable land has been lost due to housing, roads and urban infrastructure. Simultaneously, as a result of intensive agriculture, over-grazing, deforestation, water pollution and increasing use of fertilizers and pesticides, top soil has degraded considerably with increasing salinization, loss of fertility, soil erosion and desertification. Substantial rise in water usage; contamination of rivers, lakes and ground water aquifers; and discharge of increasing amount of industrial effluents, municipal sewage and non-biodegradable waste are further accelerating the process of soil degradation. Frequent droughts and flooding and other forms of extreme weather conditions due to global warming and climate change are also contributing to the process of soil degradation. As such, due to human induced activities during the last 6-7 decades, pressure on land has mounted manifold. Evidence based on research suggests that since 1950, over 35 percent of agricultural land has been degraded in varied degrees due to human induced activities.

Considering the problem of increasing land degradation and importance of soil conservation, the 68th United Nations General Assembly had declared 2015 as the International Year of Soils (IYS) vide UN Resolution 68/232 adopted on 20 December 2013 (United Nations, A/Res/68/232). The Food and Agriculture Organization (FAO) was nominated to implement the IYS 2015. A large number of seminars, conferences and public awareness campaigns were organized within the framework of the Global Soil Partnership to Combat Desertification. In the backdrop of these developments, in this article, I propose to examine the magnitude of land degradation, its threat to food security and urgent need for remedial measures.

\section{Soil Formation}

Total land area of the Earth is estimated at 148,940,000 km2 with arable land of 13,958,000 km2 or 1.4 billion hectares. Thus, the arable land constitutes less than 10 percent of the total land area of the Earth (Our World in Data, 2018). Based on the current global population, arable land per person works out to only 0.1956 hectare. According to FAO terminology, total agricultural area has been estimated at 4.889 billion hectares consisting of arable land (28\%), permanent crops (3\%) and meadows and pastures (69\%) (Our World in Data, 2018).

Soil is called the skin of the Earth (Miller, 1953). Soil determines the fertility of land, crop type and yield and thus, is 
the most significant natural resource. FAO defines soil as a naturally evolved body of matter consisting of layers (soil horizons) that are composed of weathered mineral materials, organic material, air and water. Soil is the end product of the combined influence of climate, topography and organisms (flora, fauna and human) on parent materials (original rocks and minerals) over time. Thus, soil differs from its parent material in composition, texture, structure, color, chemical, biological and physical characteristics (FAO Soils Portal, 2018). According to World Wildlife Fund (WWF), "Soil is the earth's fragile skin that anchors all life on earth. It is comprised of countless species that create a dynamic and complex ecosystem and is among the most precious resources to humans". Soil formation is a complex process. Parent material (rocks and minerals), climatic conditions, the flora and fauna (including human activities), the topography of the terrain and time are the principal soil forming factors. Original rocks and minerals constantly interact with air, water, temperature and organic matter over time to give birth to soil. It's a long process of interaction and transformation whereby the original rocks and minerals dissolve with organic matter, moisture and air. Thickness of soil could vary from a few millimeters to several meters. Since the soil formation process takes hundreds of years, soil is a non-renewable resource in short-term (WWF, Soil Erosion and Degradation, 2018).

Soil provides the foundation for plant growth, a medium for water storage and supply and a habitat for organisms (Dominati, Patterson and Mackay, 2010). Soil constitutes a vital resource and an important part of the natural environment and ecosystem from which most of the global food requirements are met. Simultaneously, soil provides living space for humans and all other species of life, ecosystem services which are essential for water storage, regulation and supply, climate regulation, bio-diversity conservation and carbon sequestration (FAO, Soils, 2018). Soils provide anchorage for roots and holds water and nutrients. Soils are home to myriad micro-organisms that fix nitrogen and decompose organic matter, and armies of microscopic animals as well as earthworms and termites. We build on soil as well as with it and in it (ISRIC, 2017). Thus, soil is one of the most precious resources for sustenance of life.

With its three-state system of solids, liquids and gases; soil is a dynamic natural body that plays a crucial role in food production and the terrestrial ecosystem. Numerous physical, chemical and biological processes keep impacting on soil on a continuous basis. The world's ecosystems are impacted in a far-reaching way by the processes carried out in the soil (Pouyat et al, 2002). After the atmosphere, the soil is the next largest carbon reservoir on earth. It is also potentially the most reactive to human activities, chemical and biological processes and climate change.

\section{Land Degradation}

Land degradation - decline in land quality or impoverishment of land due to human induced activities - remains a cause of serious concern and a major global issue due to its adverse impact on food production, environment and livelihood. Barren hillsides, cracked and parched plains, water and wind eroded sites, nutrient-deficit deserted land and vast garbage dumps are visible examples of land degradation. Land degradation is often used as an umbrella term encompassing a wide variety of land conditions such as erosion, compaction, desertification, salinization, loss of nutrients, loss of bio-diversity etc. Land degradation could lead to temporary or permanent decline in the productive capacity of land depending on the severity of degradation. Drought, flooding, excessive use of chemicals, loss of nutrients, intensive and unsustainable agriculture, deforestation, urbanization, over grazing, water pollution, increasing amount of solid waste and disposal of non-biodegradable waste are considered as the most important causes of land degradation. Very often one factor leads to another triggering a chain reaction. For example, deforestation leads to flooding and flooding to soil erosion by water. Deforestation also leads to soil erosion by wind and desertification of land due to lower precipitation. Thus, the causes of land degradation are complex and often interwoven. According to FAO, land degradation is defined as a change in the soil health status resulting in a diminished capacity of the ecosystem to provide goods and services for its beneficiaries (FAO, 2014). Thus, land degradation involves actual or potential loss of productivity and ecosystem services or impoverishment of land due to overuse; mismatch between land quality and land use; human-induced physical, biological and chemical processes and natural hazards.

Although the estimates of land degradation and their intensity vary widely (between 35 to 55 percent), they are still good enough to understand the magnitude of human-induced land degradation. Such variances are natural, given the fact that there is no precise universally accepted definition of land degradation. Moreover, the magnitude and intensity of degradation is not easy to assess despite development of new scientific approaches. Most of these estimates are based on individual and institutional researches within the confines of limited number of parameters (such as erosion, loss of nutrients, salinization etc.). In terms of methodology, some estimates are based on physical surveys, some on national satellite surveys and some on regional and international collaboration such as Global Assessment of Soil Degradation (GLASOD).

According to Costanza et al, 35 percent of world's arable land has already been degraded while further degradation continues unabated. Intensive agriculture alone, is leading to erosion, salinization or water-logging of possibly 6 million hectares per year (Costanza et al, 1997 p. 13). Soils in 38 percent of the cultivated area and 11 percent of the vegetative 
area in the world have been degraded in varied degrees since 1945 (Gardiner \& Miller, 2004). This is an area of the size of China and India put together. According to Bakker, 24 billion tons of topsoil is lost annually, which is equivalent to about 9.6 million hectares of land (Bakker, 1990). The National Research Council of the United States has estimated that during the second half of the $20^{\text {th }}$ century, productive land was lost @ 70,000 km² per year (National Research Council of US, 1999 p. 94). According to Bai et al, globally, over $20 \%$ of cultivated areas, $30 \%$ of forests and $10 \%$ of grasslands are suffering from varying degree of degradation, adversely affecting the livelihood of about 1.5 billion people. Land degradation is the combined result of numerous factors including unsustainable cultivation practices, over grazing, deforestation, soil erosion and climatic variations (Bai et al., 2008).

The World Commission on Environment and Development (WCED) is of the view that the short-sighted policies and excessive pressure on land are leading to degradation land on almost every continent: soil erosion in North America; soil acidification in Europe; deforestation and desertification in Asia, Africa and Latin America; and waste and pollution of water almost everywhere (WCED, 1987 p. 125). According to WWF, conversion of forests and natural grasslands to farm fields for cultivation and transition from natural vegetation to intensive commercial crops such as coffee, cotton, palm oil, soybean and wheat has resulted in increased soil erosion beyond soil's ability to adapt and maintain itself. In addition, soil quality has also been affected by compaction, loss of soil structure, nutrient deficiency and soil salinity. According to WWF, half of the topsoil on the planet has been lost in the last 150 years (WWF Soil Erosion and Degradation, 2018). Soil compaction is a world-wide problem, especially with the adoption of mechanized agriculture. Soil compaction has resulted in yield reductions of 25 to $50 \%$ in some regions of Europe and North America (Ericksson et al., 1974). There are serious productivity losses up to 20 percent caused by soil erosion in Asia, especially in India, China, Iran, Israel, Jordan, Lebanon, Nepal, and Pakistan (Dregne, 1992).

FAO estimates that about 52 percent of agricultural land world-wide amounting to more than 2 billion hectares, is moderately or severely degraded, adversely affecting 1.5 billion people with a disproportionately high adverse impact on women, children and rural poor (FAO, Land and Water, 2018). According to European Environment Agency, population growth coupled with urbanization is putting soils under pressure. Intensive agricultural is making soils more prone to erosion while sealing of soil surfaces due to increased urbanization and new infrastructure is the main cause of soil degradation in the most industrialized and populated countries of western and northern Europe. Localized contamination and diffuse contamination due to acidification of heavy metals are other important causes for soil degradation. For 12 members of the European Union, the estimated number of potentially contaminated sites adds up to 1,500,000. (EEA, Soil Degradation, 2017).

A study undertaken by the Ghent University in Belgium on "Production scenarios and the effect of soil degradation on long-term food security in China" in 2009; concluded that food crops in China may experience nine percent loss in productivity by 2030 if the land degradation continues at the current rate. Productivity losses are expected to increase to 30 percent by 2050 should the soil be degraded at twice the current rate. The loss of cropland is likely to cause a 13-18 percent decline in China's food production capacity by 2030-2050 compared to 2005 when the production was $482 \mathrm{Mt}$. Thus, food supply may deteriorate considerably from 18 percent surplus in 2005 to up to 22 to 32 percent deficit by 2050 (Ye \& Ranst, 2009).

A comprehensive study on land degradation in India was undertaken by the Space Application Centre (SAC), Indian Space Research Organization (ISRO), Ahmedabad. The study titled "Desertification Status Mapping of India" based on satellite data collected by IRS AWiFS (Indian Remote Sensing Satellite -- Advanced Wide Field Sensor) for 2003-05 and 2011-13 was published in 2016. This is the most comprehensive study on land degradation in India so far. According to the study, during 2011-13, 96.40 million hectares or 29.32 percent of total geographic area (TGA) of the country was undergoing process of land degradation compared to 94.53 million hectares or 28.76 percent of TGA in 2003-05. Thus, there is an increase of 1.87 million hectares of land under degradation within a period of 8 years. State-wise data reveal that Rajasthan, Maharashtra, Gujarat, Jammu \& Kashmir, Karnataka, Jharkhand, Odisha, Madhya Pradesh and Telangana contributed 81.68 percent of total land degradation in the country in 2011-13 and 82.19 percent in 2003-05. Each of the remaining states are contributing less than 1\% (individually) of desertification/land degradation.

During the same time frame, increased desertification/land degradation were observed in the states of Delhi, Tripura, Nagaland, Himachal Pradesh and Mizoram ranging between 4.34 percent to 11.03 percent, whereas Odisha, Rajasthan, Telangana and Uttar Pradesh showed marginal improvement (from -0.11 to -1.27 percent). The most significant process of desertification/ land degradation in the country is water erosion (10.98 percent in 2011-13 and 10.83 percent in 2003-05) followed by the process is vegetation degradation (8.91 percent in 2011-13 and 8.60 percent in 2003-05), and wind erosion (5.55 percent in 2011-13 and 5.58 percent in 2003-05) (SAC, 2016).

According to the concept paper prepared for the Global Symposium on Soil Organic Carbon organized by FAO in March 2017; soils have become one of the most vulnerable resources in the world due to ongoing challenges of climate 
change, loss of bio-diversity and land degradation in a variety of ways. Despite enormous scientific and technological progress for conservation of soil, land degradation continues to face a variety of challenges on the ground, since there is still insufficient global support for the protection and sustainable management of the world's soil resources. The paper highlights that the soils host the largest terrestrial carbon pool (estimated 1,500 $\pm 230 \mathrm{GtC}$ in the first meter of soil, nearly twice as much as atmospheric carbon pool of $828 \mathrm{GtC}$ ) and play a crucial role in the global carbon balance by regulating dynamic bio-geo-chemical processes and the exchange of greenhouse gases (GHG) with the atmosphere (FAO, Global Symposium on Soil Organic Carbon, 2018).

A comprehensive study undertaken by International Soil Reference and Information Centre (ISRIC) on land degradation between 1987 and 1990 revealed that soil was constantly at risk from degradation by erosion, salinity, contamination and mismanagement. The study revealed that over-exploitation, over-grazing, inappropriate clearing techniques and unsuitable land use practices have resulted in severe nutrient decline, water and wind erosion, compaction and salinization. The degradation process has especially affected the marginally suitable lands that were taken into cultivation due to population pressure but was not given enough time to recuperate after prolonged cultivation. Four principal causes of soil degradation identified in the study are; water erosion, wind erosion, chemical deterioration and physical deterioration (ISRIC, 2016). Land degradation could manifest in a variety of forms; such as loss of fertility, water logging, flooding and landslides, salinization, loss of bio-diversity and desertification.

The Global Assessment of Soil Degradation (GLASOD) project jointly undertaken by ISRIC and UNEP has produced a world map of human-induced soil degradation. Although, undertaken two decades ago, GLASOD has been the most important and most comprehensive global survey of land degradation so far. Global data were compiled with the help of 290 national collaborators and moderated by 23 regional scientists, using uniform guidelines and international correlation during 1987-1990. The status of soil degradation was mapped (Image 1) within loosely defined physiographic units (polygons), based on expert judgement. Based on global data and expert judgements, 1964 million hectares of land was found degraded in varying degrees world-wise, constituting about 22 percent of agriculture, pasture, woodlands and forests (Oldeman et al., 1991). While the GLASOD is not without criticism, the study provides a comprehensive data base of global land degradation. There is an urgent need for a similar study to ascertain the current global status of soil degradation.

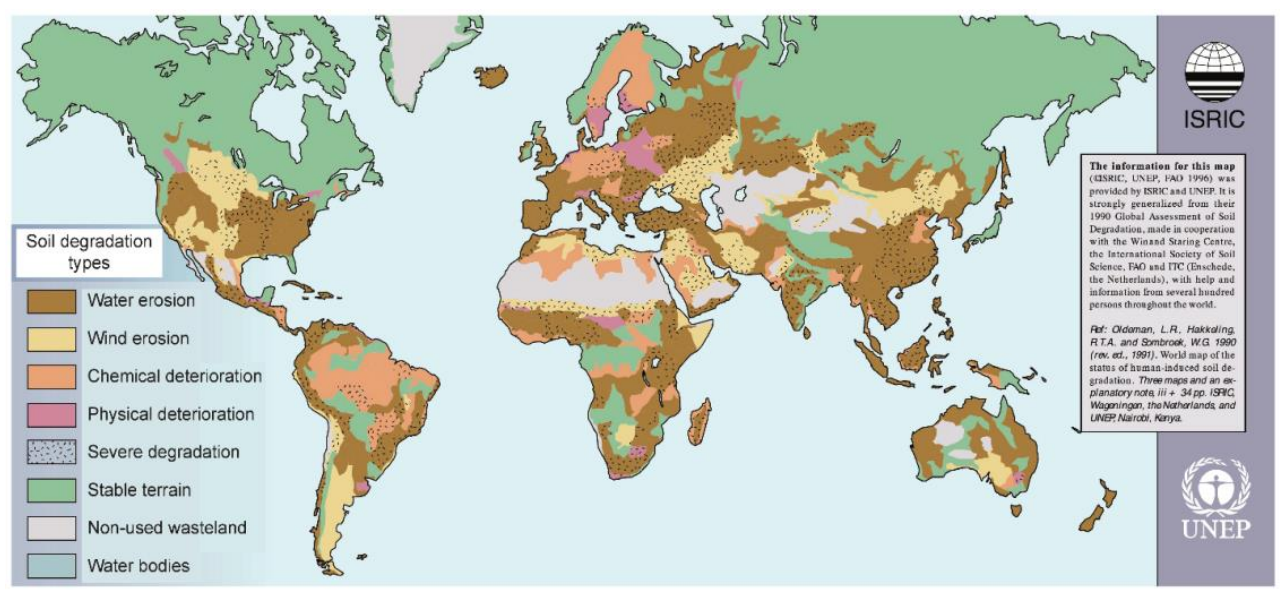

Figure 1. World Map Showing Human Induced Soil Degradation (International Soil Reference and Information Centre, 2017)

The GLASOD study concluded that (a) the past and present human intervention in the utilization and manipulation of environmental resources have been poorly understood and are having unanticipated consequences, (b) indiscriminate destruction of forests and woodlands is resulting in large-scale degradation of land and (c) that the soils are being rendered sterile or contaminated with toxic chemicals at a rate that cannot be sustained (d) loss of soil organic carbon and nitrogen related to degradation reduces the ability of the agricultural sector to produce enough food for growing global population and significantly contributes to climate change and (e) soil degradation needs to be recognized, along with climate change, as one of the most pressing problems facing humanity.

Marginal degradation can reduce the crop yield by 10 percent, moderate somewhere between 10 and 50 percent while severely degraded soil can reduce the crop yield by over 50\%. Natural disasters like flooding and landslides can occur more frequently due to soil degradation. It can also result in turbidity of water while the contribution of nitrogen and phosphorus can result in eutrophication. Additionally, soil degradation could involve perturbation of microbial communities, disappearance of the climax vegetation and decrease in animal habitat, thus leading to loss of 
bio-diversity and animal extinction. Since the functioning of nature is a complex phenomenon with multiple factors and their inter-woven influences, it is not easy to predict the precise impact of individual factors adversely affecting the quality of land.

Despite negative indicators and global pessimism, there is still a ray of hope. Given the technological advances that have been made in recent years and the greater scientific understanding of the issues today, all types of soil degradation are potentially reversible, as long as there is sufficient public support, understanding and political will (Sustainable Food Trust, 2015). Governments, scientific community and the civil society must come together to tackle this menace before it's too late.

\section{Economic Consequences of Soil Degradation}

Natural resource accounting is a relatively new concept. While the accounting of minerals is generally based on their market value, accounting for soil and water are not easy to arrive at. So far, there are no universally accepted norms for arriving at the economic cost of land degradation. The replacement cost method estimates the amount of soil nutrients lost each year and the cost of buying fertilizers to replace these nutrients. On the other hand, loss of production method is based on the economic cost of annual crop-loss due to reduced soil productivity. Many scientists believe that the cost of soil degradation must also take into account the other adverse consequences of land degradation such as flooding, erosion, loss of bio-diversity, loss of unique landscape and so on. Hence the third method is based on total economic value. Since the factors causing impoverishment of land are multiple with chain reaction and complex interaction and unanticipated consequences, it will never be easy to arrive at an accurate assessment of cost and the agreed method of accounting. Moreover, since the estimates concerning intensity of soil degradation themselves vary considerably, arriving at the economic cost of soil degradation is a daunting task. Given these ground realities, wide variations in the economic cost of land degradation are natural.

The first estimate of the global cost of soil degradation, based on the loss of production method, was $\$ 26$ billion per annum for world drylands, made by UNEP in 1980, shortly after the UN Plan of Action to Combat Desertification was agreed to, at the United Nations Conference on Desertification (UNCOD) in 1977 (UNEP, n.a.). This estimate was based on reports by consultants/experts submitted to UNEP. FAO's Land Degradation Assessment in Drylands (LADA) Project estimated annual global cost of land degradation at US\$40 billion in 1992 without taking into account the hidden costs of increased fertilizer use, loss of biodiversity, water quality, regulating the global carbon cycle and loss of unique landscapes. Global reduction in soil services as a result of unsustainable management of land has been estimated at $\$ 1$ trillion annually (FAO, Land and Water, 2018).

In some cases, the estimates of economic costs of land degradation have calculated as percentage of Gross Domestic Product. They vary widely from country to country and region to region. United Nations Convention to Combat Desertification (UNCCD) in its While Paper I on Economic and Social Impacts of Desertification, Land Degradation and Drought presented in 2013 in Bonn, Germany estimated land degradation costs for Burkina Faso 9\%, Niger 8\%, Mali $12.5 \%$, India $2 \%$, and US $0.4 \%$ of GDP for 1980 s. In case of China the direct economic cost was estimated at RMB 40 billion in 1999 (UNCCD, 2013). Tata Energy and Resources Institute (TERI) has projected the economic cost of land degradation in India in 2014-15 at 2.54 percent of GDP (TERI, 2018).

According to a study by Eswaran, Lal and Reich undertaken in 2001 and posted on the United States Department of Agriculture's website, puts the total cost due to soil degradation in US alone, at $\$ 44$ billion annually @ \$247 per hectare of cropland and pasture. The study further states that globally, annual loss of 75 billion tons of soil, costs about $\$ 400$ billion each year. As regards Africa, the study estimates an average decline of crop yield @ 8.2 percent for the continent as a whole. In South Asia annual loss of productivity has been estimated at 36 million tons of cereal equivalent amounting to $\$ 7.2$ billion. The study concludes that globally about 2.5 million $\mathrm{km}^{2}$ of land are under low risk, 3.6 million $\mathrm{km}^{2}$ are under moderate risk, 4.6 million $\mathrm{km}^{2}$ are under high risk, and 2.9 million $\mathrm{km}^{2}$ are under very high risk (USDA, 2016). Ephraim Nkonya et al., had arrived at the global cost of land degradation due to land use and land cover change (LUCC) based on total economic value approach at \$231 billion per year or 0.46 percent of global GDP of $\$ 56.49$ trillion in 2007 (Nkonya et al., 2016).

In addition to the direct economic costs of land degradation illustrated above, there is a large element of indirect consequential cost based on a complex matrix resulting in a chain of influences. For example, soil erosion by water can result in silting of rivers and reservoirs, soil erosion by wind can cause dust storm leading to health hazards. Soil erosion can also cause flooding and landslides which in turn can adversely affect bio-diversity and future precipitation. Loss of income, unemployment and food shortages due to reduced productivity can have serious social and economic consequences. 1.5 billion people mainly in the developing countries of sub-Saharan Africa and South Asia, are dependent for their livelihood on degrading agricultural land (UNCCD, 2018). They run the risk of losing their livelihood. Since the indirect influences of land degradation are highly complex and interwoven, it is not easy to fully 
grasp and anticipate their economic costs and social consequences.

Prevention is better than cure. Given a long and arduous process of soil formation, prevention is the best option to mitigate land degradation. Hence, sustainable land management (SLM) must be adopted as an important global strategy for combating land degradation. SLM has tremendous potential to help and support small and marginal farmers, reduce poverty and hunger, prevent erosion, mitigate loss of biodiversity and risk of climate change, improve management of water resources and increase food security. Degraded land is costly to reclaim and, if severely degraded, may no longer provide a range of ecosystem functions and services. Land Degradation Assessment in Dryland (LADA) undertaken by FAO in China, Philippines, Tunisia, South Africa, the Netherlands and Argentina between 2006 and 2010 have confirmed such adverse impacts of soil/land degradation (FAO, Land Degradation Assessment in Dryland, 2014). UNCCD issued a warning on June 15, 2018 that the global economy could lose \$23 trillion by 2050 due to land degradation. Preventive action if taken immediately, would cost $\$ 4.6$ trillion only (UNCCD, 2018). Global cooperation to introduce sustainable land management is therefore essential and must be accorded high priority.

\section{Challenges of Food Security}

Food is basic human need. Agriculture is the primary source of our food. According to Costanza et al, nearly 97 percent of our food comes from land (Costanza et al.,1997). Fast growing global population has put unprecedented demand on agriculture. Global population in 1900 was estimated at 1.65 billion (Our World in Data, 2017). In 2016 global population was estimated at 7.4 billion (Population Reference Bureau, 2016). The United Nations estimates that the global population will further increase to a minimum of 9.1 billion by 2050 and 11.2 billion by 2100 (UN Population Division, 2015). However, according to the medium variant projection of the UN, the global population in 2050 could even reach 9.7 billion. The Table I given below provides details of continent-wise growth of the population in the coming decades based on medium variant projection by the United Nations. From these statistics it is apparent that the growth of population is much faster in the poorer developing countries of the world where not only hunger, poverty and malnutrition are endemic but pressure on land and degradation of soil is also the maximum.

\section{Population of the World and the Continents according to the Medium-Variant Projection}

(Population in millions)

Table 1. United Nations, Department of Economic and Social Affairs, Population Division (2015)

\begin{tabular}{lcccc}
\hline Area & $\mathbf{2 0 1 5}$ & $\mathbf{2 0 3 0}$ & $\mathbf{2 0 5 0}$ & $\mathbf{2 1 0 0}$ \\
World & 7349 & 8501 & 9725 & 11213 \\
Africa & 1186 & 1679 & 2478 & 4387 \\
Asia & 4393 & 4923 & 5267 & 4889 \\
Europe & 738 & 734 & 707 & 646 \\
Latin America & 634 & 721 & 784 & 721 \\
North America & 358 & 396 & 433 & 500 \\
Oceania & 39 & 47 & 57 & 71 \\
\hline
\end{tabular}

The ten most populated countries in the world are; Bangladesh, Brazil, China, India, Indonesia, Mexico, Nigeria, Pakistan, Russian Federation and the United States of America. These 10 countries with a total population of 4.4 billion account for nearly 60 percent of global population. Asian nations are contributing maximum to the global population growth followed by Africa (World Population Prospects, United Nations, 2015).

The task of feeding an additional 1.7 to 2.3 billion people by 2050 with increasing degradation of soil and the ever-growing risk of climate change is a major challenge facing the humanity. The projections by FAO indicate, that feeding a world population of 9.1 billion in 2050 would require raising overall food production by about 70 percent between 2005/07 and 2050. Production in the developing countries would need to grow must faster. Annual cereal production, would have to grow by almost one billion tons, meat production by over 200 million tons to a total of 470 million tons by 2050 . Feeding the world population adequately would also necessitate producing the kinds of foods that are needed to ensure nutrition security. This is indeed a daunting task, particularly with deteriorating natural environment (FAO, How to Feed the World 2050, 2009). Moreover, shortage of agricultural labor and economic profitability are also operating as a major constraint in food production in the developed countries.

In addition to the challenge of feeding the growing world population, the challenge of feeding under-nourished and hungry puts additional burden on food production and distribution. Despite encouraging progress under Millennium Development Goals (MGDs), vast pockets of hunger and poverty are still prevalent across the globe. The United 
Nations Food and Agriculture Organization (FAO) estimates that about 795 million people of the 7.4 billion people in the world, or one in nine, were suffering from chronic undernourishment in 2014-2016. More than 98.6 percent the under-nourished people, 784 million, live in the developing countries while the remaining 11 million are in the developed countries (FAO, State of Food Insecurity in the World, 2015). Unfortunately, children are the most adversely affected section of humanity due to hunger and malnutrition. 3.1 million children are estimated to die annually due to hunger and malnutrition while another 161 million under the age of five are stunted (World Hunger, 2016). Inclusive growth, is a key factor in order to eliminate hunger and starvation.

Wastage of a large quantity of food is yet another challenge. According to a recent report by United Nations Environment Programme (UNEP) and the World Resources Institute (WRI), about one-third of all food produced worldwide gets lost or wasted in food production, transportation and consumption chains. This amounts to approximately $\$ 1$ trillion per annum. Converted to calories, this means that about 25 percent of calories are lost in this chain and never consumed. In US, 30-40 percent of the food is wasted, amounting to more than 20 pounds of food per person per month. Ironically, wasted food is also a major source of organic waste in US, which in turn, is one of the largest sources of methane emissions (UNEP, 2015). In a world full of hunger, volatile food prices, and social injustice, these statistics are more than just shocking: they are environmentally, morally and economically outrageous.

Between 1950 and 1985 cereal production increased from around 700 million tons to over 1800 million tons at an annual growth rate of around 2.7 percent. World food production in 2010 was estimated around 2200 million tons (Figure 2). Increased food production helped to meet the escalating demand due to population growth and rising per capita income. This unprecedented growth in food production was achieved partly through expansion of arable land and partly due to rise in productivity through high yielding pest resistant seed varieties, use of more chemical fertilizers (increase by 9 times), use of more pesticides (increase by 32 times) and increased irrigated area (WCED, 1987 pp.118-123). Arable land in Asia, Africa and Latin America has expanded by about 5 million hectares per year during the last five decades. Over the past 50 years, the world's net cultivated area has grown by $12 \%$, mostly at the expense of forest, wetlands and grassland habitats (FAO, 2011). At the same time, the global irrigated area had expanded to 324 million hectares in 2012. This amounted to 41 percent of total cultivated area as against 26 percent in 1970 (FAO, 2016). However, increase in food production through increased area, more irrigation, high yielding varieties and use of more chemical fertilizers and pesticides has reached its saturation. Moreover, increasing production without much attention to sustainability is fraught with ecological consequences.

Changing dietary habits is yet another important factor in global food security. It is well established scientific fact that vegetarian diet is far more environment-friendly than meat based dietary habits. With rising per capita income and urbanization more and more people tend to eat meat and meat products. Per capita yearly consumption of meat and meat products was $24.2 \mathrm{~kg}$ in $1966-68,36.4 \mathrm{~kg}$ in $1997-99$ and is likely to be $45.3 \mathrm{~kg}$ in 2030 . Per capita yearly meat consumption in the rich industrialized nations is more than double the global average (WHO, Nutrition, 2018). With growing meat demand, world's livestock sector is growing at a very fast pace. Today it is the single largest contributor of greenhouse gases with 14.5 percent of total emissions and a large user of natural resources. It takes about $6.5 \mathrm{~kg}$ of grain and 15000 liters of water to produce one $\mathrm{kg}$ of beef and $4 \mathrm{~kg}$ of grain and 6000 liters of water to produce one $\mathrm{kg}$ of pork (FAO, Livestock-Environment 2018). Thus, increasing tendency towards meat-based diets necessitate higher production of cereals, considerable consumption of water resources and massive emission of greenhouse gases.

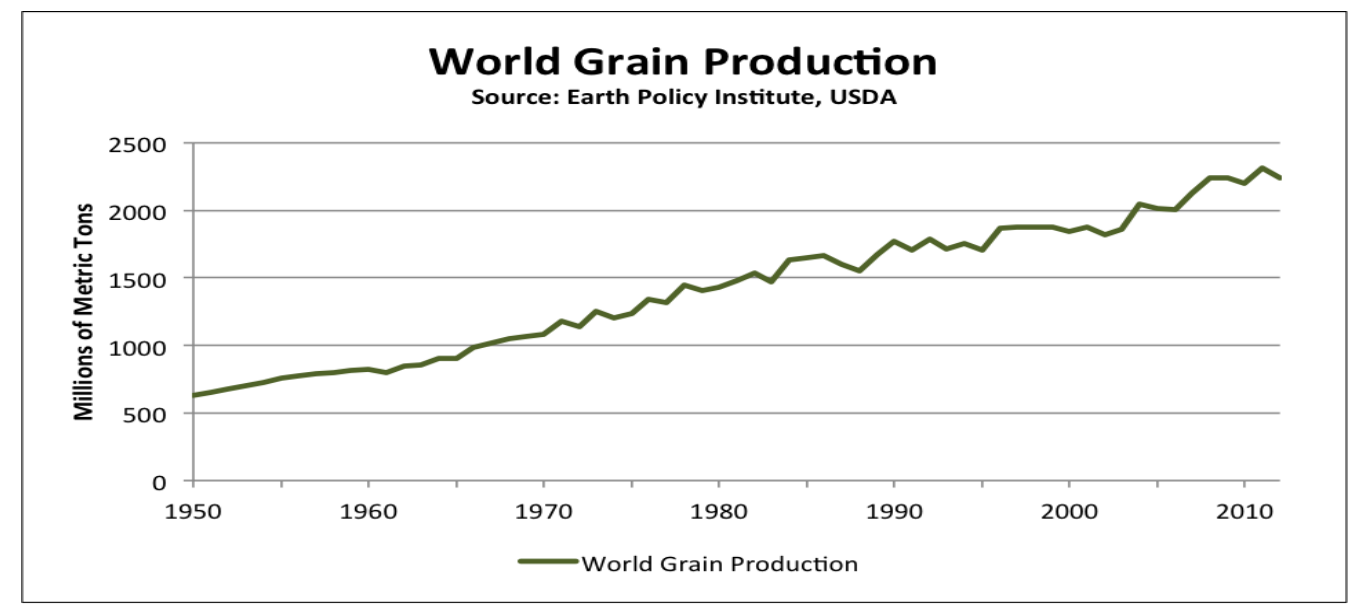

Figure 2. World Grain Production 1960-2010 (Earth Policy Institute, USDA, 2018)

Thus, agriculture in the 21 st century faces multiple challenges. It has to produce more food and fiber to feed a growing 
population. Demand for cereals, for both food and animal feed uses are projected to reach some 3 billion tons by 2050, up from today's nearly 2.1 billion tons. Expansion of arable land is unlikely without deforestation. Extension of irrigation facilities to cultivated land are also nearing saturation. On the contrary, the crop area is estimated to decline by 2050 due to housing for enhanced population and need for services and infrastructure. Simultaneously, soil degradation is taking place at an enhanced pace due to increasing pressure on land both for habitation and agriculture (including commercial agriculture). Water resources are also under pressure due to rising needs for agriculture, industries and municipal use. Erratic climatic conditions including frequent flooding and droughts are further aggravating the situation. These challenges are indeed massive particularly when the arable land is shrinking and soil degradation is increasing every passing day. According to FAO, crop yields would continue to grow but at a slower rate than in the past. This process of decelerating growth has been already in motion for some time. On average, annual crop yield growth rate during the current decade is likely to be about half ( 0.8 percent) of its historical growth rate of 1.7 percent and then decline further (FAO, How to Feed the World 2050, 2009). A report prepared by Barilla Center for Food Nutrition estimates, that the decline and conversion of croplands use could cause a reduction in cultivated land area of 8-20\% by 2050. The combined effects of climate change, land degradation, cropland losses, water scarcity and species infestations may cause food shortages in the range of 5-25 percent by 2050 (Barilla Center for Food Nutrition, 2009).

Therefore, the challenges of food security are many. Apart from soil degradation, growing population, water scarcity, climate change, declining yield, changing food habits, food losses in the production-consumption chain and unsustainable land use are some of the main challenges. Unfortunately, agriculture is fairly low in the national priorities of many nations. Rapid industrialization is considered as the mantra for development. Soil is still considered as 'dirt' and a farmer is looked down as under-educated semi-cultured person. Increasing number of natural calamities are also playing havoc with agricultural production adding to the risk of farmers. Educated people in most countries want to stay away from farming as it involves hard labor and high risk and provides no social status and modern comforts. Moreover, in many countries farmers are unable to fetch fair prices for their products making agriculture economically less attractive. Minimum support prices and agricultural subsidies are considered against market norms and violative of WTO rules and of course a big drain on budgetary resources.

Given the challenges of food security, policy-makers and society must ponder over all these issues. Farmers deserve much higher respect and recognition from the governments, policy makers and the society at large. It is time to develop new thinking towards agriculture to make it more remunerative and to introduce sustainable farming practices. Sustainable farming practices must form an essential part of educational curriculum. New models of social organization and behavior are needed to support lifestyle patterns of consumption that are more sustainable. Tendency towards growing meat consumption need to be discouraged given its adverse impact on environment. Environmental foot-print of vegetarian diet is much lower. Wastage and over-consumption are behaviors that we can ill-afford. Technological advances must be used for conservation of soil, reduction of water-logging and salinization, judicious use of fertilizers and pesticides and reduction of food losses. An increased awareness towards environmental ethics; including conservation of forests, reduction in non-biodegradable waste, preservation of water bodies and optimal use of water resources, are essential needs if we wish to avoid food shortages and famines in the decades ahead.

\section{References}

Bai, Z. G., Dent, D. L., Olsson, L., \& Schaepman, M. E. (2008). Global assessment of land degradation and improvement. 1. Identification by remote sensing. Report 2008/01, ISRIC - World Soil Information: Wageningen

Bakker, H. J. I. (ed.) (1990). The World Food Crisis: Food Security in Comparative Perspective. Canadian Scholars Press, Toronto, 530.

Dominati, E., Patterson, M., \& Mackay, A., (2010). A framework for classifying and quantifying the natural capital and ecosystem services of soils from: https://www.researchgate.net/publication/223852147_A_framework_for_classifying_and_quantifying_the_natural _capital_and_ecosystem_services_of_soils

Dregne, H. E. (1992). Degradation and Restoration of Arid Lands. Lubbock, Texas Technical University.

Earth Policy Institute. (2010). World Grain Production 1960-2010. Retrieved from: http://www.earth-policy.org/datacenter/pdf/book_wote_crops.pdf

Eriksson J., Hakansson I., \& Danfors, B. (1974). The Effect of Soil Compaction on Soil Structure and Crop Yields. Bulletin 354. Uppsala: Swedish Institute of Agricultural Engineering.

European Environment Agency. (2017). Environment in the European Union at the Turn of the Century, chapter 3.6 soil degradation. Retrieved from: http://www.eea.europa.eu/publications/92-9157-202-0/page306.html

Food and Agriculture Organization. (2009). Global Agriculture towards 2050. How to Feed the World 2050. Retrieved 
from:http://www.fao.org/fileadmin/templates/wsfs/docs/Issues_papers/HLEF2050_Global_Agriculture.pdf

Food and Agriculture Organization. (2011). The State of the World's Land and Water Resources for Food and Agriculture. Food and Agriculture Organization of the United Nations: Rome, Italy; Earthscan: London, UK, 2011. Retrieved from: http://www.fao.org/docrep/017/i1688e/i1688e.pdf

Food and Agriculture Organization. (2014). Land Degradation Assessment in Dryland. Retrieved from: http://www.fao.org/nr/lada/ and http://www.fao.org/nr/land/degradation/en/

Food and Agriculture Organization. (2015). State of Food Insecurity in the World. Retrieved from: http://www.fao.org/3/a-i4671e.pdf

Food and Agriculture Organization. (2016). Food and Agriculture Data. Retrieved from: http://www.fao.org/faostat/en/\#home

Food and Agriculture Organization. (2018). Global Symposium on Soil Organic Carbon, Retrieved from: http://www.fao.org/about/meetings/soil-organic-carbon-symposium/en/ [Accessed on 29 March 2018].

Food and Agriculture Organization. (2018). Land and Water. Retrieved from: http://www.fao.org/land-water/land/httpwwwfaoorgsoils-portalen/en/

Food and Agriculture Organization. (2018). Land and Water. Retrieved from: http://www.fao.org/land-water/land/land-assessment/en/

Food and Agriculture Organization. (2018). Livestock-Environment, Retrieved from: http://www.fao.org/livestock-environment/en/

Food and Agriculture Organization. (2018). Soil Portal, Key Definitions. Retrieved from: http://www.fao.org/soils-portal/about/all-definitions/en/

Gardiner, D. T., \& Miller R. W. (2004). Soils in our environment. $10^{\text {th }}$ edition. Prentic-Hall, Inc. Upper Saddle River, New Jersey, USA.

International Soil Reference and Information Centre. (2017). Retrieved from: https://www.isric.org/discover/about_soils

International Soil Reference and Information Centre. (2017). Retrieved from: https://www.isric.org/discover/about_soils/threats and http://www.isric.org/projects/global-assessment-human-induced-soil-degradation-glasod

Miller, A. (1953). The Skin of the Earth London, UK: Methuen and co. Ltd. Retrieved from: https://archive.org/details/skinoftheearth032705mbp

National Research Council of the National Academies of US. (1999). Our Common Journey-a transition toward-Sustainability. National Academy Press, Washington D.C.

Nkonya, E. M., Weston, A., Kato, E., Koo, J., Alisher, M., von Braun, J., \& Meyer, S. (2016). Global Cost of Land Degradation. https://doi.org/10.1007/978-3-319-19168-3_6

Oldeman, L. R., Hakkeling, R. T. A., \& Sombroek, W. G. (1991). World Map of the Status of Human-induced Soil Degradation: An Explanatory Note. ISRIC/UNEP, Wageningen, The Netherlands.

Our World in Data. (2017). World Population Growth 1750-2015. Retrieved from: https://ourworldindata.org/world-population-growth

Our World in Data. (2018). Yield and Land Use in Agriculture. Retrieved from: https://ourworldindata.org/yields-and-land-use-in-agriculture

Population Reference Bureau. (2016). 2016 World Population Data Sheet. Retrieved from: http://www.prb.org/Publications/Datasheets/2016/2016-world-population-data-sheet.aspx

Pouyat, R., Groffman, P., Yesilonis, I., \& Hernandez, L. (2002). Soil Carbon Pools and Fluxes in Urban Ecosystem Retrieved from: https://ecologicalprocesses.springeropen.com/articles/10.1186/s13717-014-0023-8

Robert, C., Cumberland J., Herman, D., Goodland R., \& Norgaard, R. (1997). An Introduction to Ecological Economics. Boca Raton, Florida, St. Lucie Press.

Sheeran, J. (2009). The Challenges of Food Security, Center for Food Nutrition. Retrieved from: https://www.barillacfn.com/m/publications/pp-challenges-food-security.pdf

Space Application Centre. (2016). Desertification and Land Degradation Atlas of India. Retrieved from http://www.sac.gov.in/SACSITE/Desertification_Atlas_2016_SAC_ISRO.pdf 
Sustainable Food Trust. (2015). Soil Degradation: A Major threat to Humanity. Retrieved from: http://sustainablefoodtrust.org/wp-content/uploads/2013/04/Soil-degradation.pdf

Tata Energy and Resources Institute. (2018). Retrieved from: http://www.teriin.org/infographics/economic-cost-land-degradation-india

United Nations - Department of Economic and Social Affairs. (2015). Population Division. Retrieved from: https://esa.un.org/unpd/wpp/DataQuery/

United Nations Convention to Combat Desertification. (2013) White Paper I on Economic and Social Impacts of Desertification, Land Degradation and Drought, Retrieved from: https://profiles.uonbi.ac.ke/jmariara/files/unccd_white_paper_1.pdf

United Nations Convention to Combat Desertification. (2018). Retrieved from: https://www.unccd.int/news-events/poor-land-use-costs-countries-9-percent-equivalent-their-gdp-0

United Nations Environment Programme. (2015). The World Food Day, Food Waste-The Facts. Retrieved from: http://www.worldfooddayusa.org/food_waste_the_facts

United Nations Environment Programme. World Status of Desertification. Retrieved from: https://na.unep.net/siouxfalls/des/uncedp1.php

United Nations General Assembly. A/RES/68/232. International Year of Soils. Retrieved from: http://www.un.org/en/ga/search/view_doc.asp?symbol=A/RES/68/232\&Lang=E

United Nations. (2015). World Population Prospects, The 2015 Revision. Retrieved from: https://esa.un.org/unpd/wpp/publications/files/key_findings_wpp_2015.pdf

United States Department of Agriculture. (2018). Natural Resources Conservation Service - Soils. Retrieved from: https://www.nrcs.usda.gov/wps/portal/nrcs/detail/soils/use/?cid=nrcs142p2_054028

World Commission on Environment and Development. (1987). Our Common Future. Oxford University Press.

World Health Organization. (2018). Nutrition, Retrieved from: http://www.who.int/nutrition/topics/3_foodconsumption/en/index4.html

World Hunger. (2016). 2016 World Hunger and Poverty Facts and Statistics. Retrieved from: http://www.worldhunger.org/2015-world-hunger-and-poverty-facts-and-statistics/

World Wildlife Fund. (2016). Soil Erosion and Degradation. Retrieved from: http://www.worldwildlife.org/threats/soil-erosion-and-degradation

Ye, L., \& Ranst, E. V. (2009). Production scenarios and the effect of soil degradation on long-term food security in China. ELSEVIER, Global Environmental Change, 19(4), 464-481. https://doi.org/10.1016/j.gloenvcha.2009.06.002

\section{Copyrights}

Copyright for this article is retained by the author(s), with first publication rights granted to the journal.

This is an open-access article distributed under the terms and conditions of the Creative Commons Attribution license (http://creativecommons.org/licenses/by/4.0/). 